\title{
ACCOUNTING AS A REPRESENTATIONAL CRAFT: REFLEXIVE ACCOUNTING RESEARCH
}

\author{
Cheok Mui Yee and Edward Wong Sek Khin ${ }^{1}$
}

\begin{abstract}
This article discusses the scope of managerial accounting research based on agency theory, that is, behavioural decision-making, the use of capital markets and what is called positive theory. The authors believe that management accounting representations are somewhat stable, and, therefore, allow accounting researchers to theorise the form and function of representations in the organisation from a wide variety of perspectives, such as organisation theory, social theory, and corporate and manufacturing strategies. In order to justify the above analysis, the authors refer to the way in which the structuration theory of Anthony Giddens, that has been employed by Macintosh \& Scapens, argues that management accounting systems are interpretive schemes, facilities and norms used by management to make plans, take action and control others in an organisation.
\end{abstract}

Keywords: Management Accounting, Research Philosophy, Structuration Theory

\section{Introduction}

This paper presents an overview of accounting research that derives from its established craft of making representations and contrasting them with the tradition of research in other management fields, such as information systems. Hence, the authors place much emphasis on addressing the context and application issues while concentrating on issues concerning the philosophy and theory of management accounting systems. Although the authors identify the concerns in developing representations, this can strengthen research in other management systems; however, as there are many issues concerning management accounting systems, it might be more useful to portray their arguments using structuration and interpretive acts. In this instance, the authors address comments through the

\footnotetext{
Corresponding author: Dr Edward Wong Sek Khin is an Associate Professor at the Faculty of Business \& Accountancy, University of Malaya, email: edwardwong@um.edu.my.
} 
illustration of ideas, definitions, stances, arguments, and the empirical works of others in relation to management accounting systems.

In addition, the authors discuss the crucial impact of research on management accounting representations. The authors believe that management accounting reports would challenge the image of a 'monolithic set of structuring properties' (using a knowledgeable, purposive human actor who is producing and reproducing social structure through management accounting practices), and advise managers to become more potent and inventive creators of reports. This is because, as a reader of management accounting reports, managers draw from a wide range of interpretive schemes, facilities and norms in sourcing and developing their interpretations. Management accounting systems may not only mediate this interpretive process, but can do so in surprising and unexpected ways (Jonsson, 1992, 1997).

The first section of this paper introduces the literature, which outlines some of the features of accounting research developed through the established craft of making representations. The next section discusses the methodology. The third section discusses a case study from the authors, self-reflective perspective, and the last section identifies areas for future improvement.

\section{Literature review}

According to Giddens (1995) an interpretive act is a universal condition of our being in the world. Each of us is continually involved in giving meaning to the stream of events, encounters and activities that fill our days. The meaning of our actions and those around us is something we make; it is an interpretation and not something that is simply given to us. Schön and Argyris (1996) state that the making of meaning through interpretation is a skilled, personal accomplishment, and that the meanings we make are always tenuous and at risk. The meanings of things change for us and meanings that endure do so because of a series of interpretations we have made that we have produced and reproduced over time.

The authors view on interpretive acts originated from the hermeneutics school of thought. They state that hermeneutics is the study of interpretation and use the central metaphor of 'the text' to help develop our understanding of an interpretive act. Hermeneutics initially concerned the problem of interpreting ancient religious texts; however, it now refers to the general problem of textual interpretation and incorporates the metaphors of the situation and even actions as interpretable text (Jonsson, 1992, 1997).

In light of these theoretical presumptions, it would be useful to review how these presumptions, and particularly interpretive acts, are carried out in the context of accounting research. The authors are of the view that interpretive acts in accounting can be ascertained through accounting representations, which are explained in the following points. First, the features of accounting research have developed through the established craft of making representations, and there 
are limitations in the features on accounting representations compared to other management fields, such as information systems. The researchers of information systems have a craft for developing these systems, whereby accountants are crafted for developing representations. This can be revealed by the context that accountants are generally engaged in the interpretive act as both readers and writers of organisational texts. This is because accountants make interpretive readings of an organisational situation as a basis for writing records and reports. Accounting reports, in turn, are read by managers and others, as they create an understanding of various organisational situations. The interpretive act of interest to the above is the reading of accounting reports as texts by managers. It looks at how organisational actors give meaning to these accounting texts to better understand what accounting texts are and what is at stake in writing them.

Second, accounting, as a representational craft, can also be revealed by the theory of structuration and interpretive acts. The authors believe that structuration is an approach to understanding the social world that replaces the traditional dualisms of social theory with a duality of reciprocal interdependences. Dualism is the way in which traditional sociology takes central concerns, such as understanding the individual and understanding society, to be separate theoretical domains. Because of the dualism of the individual and society, traditional sociology portrays social structure as something that exists independent of human action, imposing on it from the outside, and shaping it as a mould shapes clay.

Third, in order to support the two dimensions of taxonomy on the accounting representational craft (as control system and as social interventions), the authors agree with Gidden's argument that action and structure presuppose one another. This is because social structure exists only in so far as it is instantiated in the action of individuals. An Individual's action, in turn, takes place with skilful, reflexive monitoring that draws upon an actor's knowledge of the structuring properties of given social systems. In drawing upon these structuring properties, or modalities, the individual reproduces them. They are recursively present as both the medium and the outcome of action. The authors further view that Gidden's structuration theory is thus a hermeneutic theory in that it emphasises the actor's continual effort at sense-making as the instantiation of social structure.

Fourth, with respect to accounting being representational of social interventions, these representations can reveal the application of Gidden's three modalities of structuration. They include interpretive schemes, or 'the core of mutual knowledge whereby an accountable universe is sustained'; norms, or the 'actualisation of rights and enactment of obligations' that facilitate, or reproduce relations of autonomy and dependence in social interactions. The authors view them as institutionalised practices, interpretive schemes that give rise to our modes of significant, norms that give rise to our modes of legitimating events and facilities that give rise to our modes of domination. As a result, Gidden argues that research on accounting representations displays a higher degree of reflexivity and limitation than other management fields, such as research on information systems. 


\section{Methodology}

The methodology chosen for this pilot study is qualitative, and is based mainly on Boland's (1979) notion of validity in heuristic research, as the authors began to consider Schön's (1983) admonition to be a reflective practitioner. This is in line with the emphasis of Habermas and Boland (1979) on the importance of self-reflection and in line with the thrust in qualitative research literature on the researcher's voice and signature, researcher bias, and managing subjectivity (Denzin and Lincoln, 1994, pp. 424).

The following section illustrates a pilot study in which the authors investigate the possibilities of a plantation accountant's issues as accounting research, in the hope of providing a catalyst for the development of egalitarianism.

\section{Self-reflection account on case study}

The author describes an experiment, illustrating the dominating methodological issues in the conduct of a management accounting systems seminar. Eight doctoral students and four management accountants were formed into two groups (Groups A and B each consisted of four doctoral candidates and two management accountants) and asked to think about how they, and others, might react to the differences in the intellectual achievements and typical behaviour between men and women.

The two groups stated a belief, that they could not exercise their talents to the full or give rein to their natural inclinations (personal case study No 1, June 2012). As a 'Group A' doctoral participant summarised:

"Schön (1983) describes the reflective practitioner as someone who is simply thoughtful about his or her own practice. In fact, reflective practice involves the mental process of reflecting, which may or may not be characterised by what is commonly referred to as "being reflective". Our challenge is for business practitioners, including corporate CEOs, directors, senior partners, senior managers, economists, all those involved with business and decision-making, to write professional autobiographies of their experiences, where we can see the integration of practice and theory to source the creation of academic papers and research theses. Strategic alliances with these reflective practitioner researchers will inspire market and professional reforms by the scientific, philosophical, ethical, and moral power of the Socratic tradition of questioning various points so that learning, knowledge, and the gaining of wisdom are the natural results from such university experiences. A Reflective Practitioner's research thesis is in style of journalistic writing, asking and answering questions, defending positions, and as it uses the experiences of the writer, it is a private, honest, and interesting description of events. A Reflective 
Accounting Practitioner demonstrates, and is willing to constructively share with their readers, their near-journalistic background and writing styles, which allows the readers to consider a thesis as an enjoyable and flowing interpretation of the events described."

Another participant in Group B argued that:

"Reflection on one's heuristic inquiry is an iterative process and the reflective practitioner's account relates the kind of immediate "postmortem" reflections that facilitate the dealing with issues "on the run" in a true journalistic style. A Reflective Accountant Practitioner does this by periodically taking a step back and reading through his journal and then commenting upon his reflections from his journal's entries. This is a search for insights into his personal and professional voice, in a multi-vocal, neo-pragmatic style blended with a rich picture presentation involving graphics and photographs to tell us his story. Through this approach, the Reflective Practitioner's research offers a new way of considering and pursuing an expedition into many different disciplines, among these are sociology, education, business, psychology, economic, law, and the current critical school. Reflective Practitioner's research surrounds the researcher's critical narrative commentaries by exploring how and why the researcher should address concerns about a piece of qualitative research while engaging both the existing and emerging theories of the epistemological and ontological orientation of his professional practice. Presenting these commentaries also enables the reader to form a sense of a dependable and defensible research paper. In the layout of Reflective Practitioner's critical narrative commentary, there are instructions that inform the reader about the reasons why and how he developed his writing style, a writing style approach that begins from a post-modernist perspective."

In addition, it has been shown through some studies that rural accounting participants are by nature less competitive and aggressive than city accounting participants, and, therefore, have little interest in pushing against the "glass ceiling", as they do not want to expend energy in competing with their colleagues.

When dealing with contentious issues, such as the role of rural participants in any given area of expertise, it is essential, in our opinion, that the researcher uses reflection to identify and distance themselves from their own assumptions and conditioning (Personal interviews, June 2012).

The authors conducted another experiment, this time to try to find evidence either for or against the issues about the abilities and attitudes of rural participants particularly in accounting systems management (personal case study No 2, July 2012). As 'Group B’ feminist doctoral students summarised: 
"With sufficient care we may be able to disentangle what is true in the self-reflection contention from what is false. At least we should be able to avoid the dilemma, which seems to be taken for granted by most participants in the debate, that we must say that this self-reflection style assumes that any learning situation has the potential to yield new ideas for enhancing the researcher's learning, as researchers who use this approach find that it tends to open up new possibilities by the shedding of philosophical inhibitions that would otherwise stifle this method. That is, the researcher offers an account of this innovative thinking, suggesting a framework of questions, which practitioners can use, by drawing upon the practitioner's existing knowledge to generate new insights and possibilities for further new practices. The researcher may further discover a basis for deciding which of the new possibilities to pursue in enhancing their professional practices in a real-life situation. Furthermore, when the researcher explains this approach in a real-life situation, it may be used in practice to advance the knowledge base of other professional practitioners."

Another participant argued that:

"A Reflective Practitioner's research, by natural necessity, draws upon a wide literature base, integrates it well into his work, and contributes to both theory and to possible practice. This means that a Reflective Practitioner's research aims to produce a business-oriented professional who can directly apply their doctoral level skills at the senior executive level in the business world everywhere. The result is meant to be studied by a knowledgeable 'reflective professional, 'who with their career in mind, is seeking systematic research that gives particular priority to developing business expertise through experience and, importantly, considered reflection to yield new vistas for the business professional communities. Reflective practitioner research is a way to achieve reform in the professions, maintain and improve confidence and stability including trust in marketplace governance, and professional empowerment particularly for Malaysian business communities to embark on the path of Malaysia Vision 2020. (Personal interviews, July 2012).

\section{Conclusion - Self reflection account}

On reflection, we realised that we agreed with the above participants' points of view, yet we found it difficult to understand why we were in such close agreement with them. Evidence for and against deprivation of rural participants' rights is hard to find in an accounting research context. Therefore, we found ourselves 
concluding that social pressure is the main cause of discrimination in these areas (Boland, 1993).

The authors also argue that the features of accounting research are developed through the established craft of making representations. These can be viewed from the capacity that accountants generally have from extensive experience in developing accounting statements, and which constitutes a representational craft. The above context is a further strengthening of the fact that there is 'self-imposed constraint' within an accounting practice. This means that there are limitations in the features in accounting representations compared to other fields, such as the information systems field. In addition, such limitations restrict accountants in their ability to represent different aspects of social economic systems. As a result, as yet, accounting representations that cover the environmental area through the features of environmental accounting are neither well received, nor accepted as part of accounting practices (Jonsson, 1992, 1997).

\section{Limitations of the study}

The limitations of this pilot study pertain to the information gathered through the interviews with the accounting participants. The historical construction of the data gathered rests on the integrity and knowledge of the interviewed accounting participants.

\section{References}

Boland, R.J. (1979). Control, causality and information system requirements. Accounting, Organisations and Society, Vol. 4 No.3, pp.259-72.

Boland, R.J. (1993). Accounting and the interpretive act. Accounting, Organisations and Society, Vol. 18, Issues 3, Pages 125-46.

Denzin, N.K. (1994). The art and politics of interpretation. In N.K. Denzin and Y.S Lincoln (Eds.). Handbook of qualitative research. California: Sage.

Donald Schön (1983). The Reflective Practitioner: How professionals think in action. London: Temple Smith, 1983.

Donald Schön, C. Argyris (1996). Organizational learning II: Theory, method and practice. Reading, MA: Addison Wesley, 1996.

Giddens, Anthony (1995). Politics, Sociology and Social Theory: Encounters with Classical and Contemporary Social Thought. Cambridge University Press

Jonsson, S. (1992). Accounting for Improvement: Action Research on Local Management Support', Accounting, Management and Information Technologies: Volume 2, Issue 2, 1992, Pages 99-115

Jonsson, S (1997). CATS, RATS, AND EARS: Making the case for ethnographic accounting research Accounting, Organizations and Society Volume 22, Issues 3-4, April-May 1997, Pages 367-386

Kaplan, R. (1992). Putting the Balanced Scorecard to Work. Harvard Business Review: Pages 134-147 